\title{
Age and perceived benefits are associated with willingness to participate in an electric load control program
}

This version: July 9, 2018

\author{
Authors \\ Peter D. Howe ${ }^{\mathrm{a} *}$, Johanna L. Mathieu ${ }^{\mathrm{b}}$ \\ *Corresponding author \\ ${ }^{a}$ Environment and Society \\ Utah State University \\ 5215 Old Main Hill \\ Logan, UT 84322-5215 \\ peter.howe@usu.edu \\ ${ }^{\mathrm{b}}$ Electrical Engineering \& Computer Science \\ University of Michigan \\ 1301 Beal Ave \\ Ann Arbor, MI 48109 \\ jlmath@umich.edu
}

\begin{abstract}
Load control programs allow power system operators to coordinate the power consumption of residential electric loads, such as air conditioners and refrigerators. Such programs can facilitate greater integration of variable renewable energy sources like wind and solar power into the grid. However, load control programs are uncommon in the U.S., and it is unclear what factors are associated with consumer willingness to participate in such programs. We examine the effect of demographic characteristics and types of benefits on willingness to share static and dynamic load information with the utility and participate in a load control program. A U.S. general population survey experiment presented respondents with short descriptions of refrigerator information sharing or control, with varying descriptions of benefits (including cost incentives and environmental benefits). Willingness to participate was highest
\end{abstract}


when environmental benefits were described and among younger respondents, with respondent age having the largest effect. Respondents were more willing to share static than dynamic load information. Willingness to share dynamic information and participate in load control were comparable. These results suggest that targeted communication strategies that leverage consumer preferences for environmental benefits along with individual demographic characteristics may be most effective in eliciting adoption of load control programs.

\section{Keywords}

Load control; public acceptance; environmental attitudes

\section{Background}

The transition to a low carbon energy system will likely involve changes in public policy and individual energy-related behaviors, both of which are likely to be influenced by public attitudes and values (Demski et al. 2015). Energy conservation behavior, such as willingness to adopt smart meters, has previously been shown to positively related to concern about climate change and the environment (Spence et al. 2014, 2015; Asensio and Delmas 2015). As a result, willingness to engage in new energy behaviors enabled by emerging technologies may also relate to whether the behaviors are perceived to have direct environmental or climate change mitigation benefits. One important consumer-level behavior that may improve the reliability and economic efficiency of the electrical grid and allow for increased penetration of renewable energy sources is participation in load control programs (Schuitema et al. 2017). In load control programs, utilities or third-party load aggregators send control signals to increase and decrease the consumption of large collections of spatially distributed electric loads, shifting their energy usage over time. These actions can be used to provide services, such as frequency regulation, to 
the power system operator, effectively balancing errors in load or renewable energy forecasts (Callaway and Hiskens 2011). Load control is more effective if consumers are willing to share more information about their controlled loads with the utility or aggregator. The type of information varies from static information on major household appliances (such as the make and model of refrigerators or air conditioners) to dynamic information such as appliance power demand and operating state (for example, the time-varying temperature within a refrigerator) (Mathieu et al. 2013). The extent to which individuals are willing to share load information or participate in load control programs may depend on individual and household characteristics, on the incentives provided for participation, and on how communication about information sharing and control are framed to potential participants. Here we examine the impact of the type of benefits described as attainable through participation on willingness to share static and dynamic load information with the utility and willingness to participate in load control programs. We describe a U.S. national general population survey experiment that presented participants with short descriptions of refrigerator information sharing or control, with varying descriptions of benefits (including cost incentives and environmental benefits).

Load control can support the increasing penetration of variable renewable energy sources such as wind power with ensuing environmental benefits including reduced air pollution and reduced emissions from fossil fuel generation (Vuylsteke et al. 2015). Recent engineering research has developed methods to shift load energy consumption in time while permitting the devices to continue functioning in a way that is "non-disruptive" to the consumer (Mathieu et al. 2013). Thermostatically controlled loads like air conditioners, heat pumps, refrigerators, and water heaters are particularly well-suited to load control programs because their power consumption is already flexible - they modulate temperature within a small range by switching 
on and off, but the exact timing of the switching could be adjusted by the utility. Load control can decrease the need for supply/demand balancing from fossil fuel generators, which reduces the need to operate these plants at high ramp rates which would otherwise result in high greenhouse gas emissions and air pollution such as $\mathrm{NO}_{\mathrm{x}}$ (Katzenstein and Apt 2009).

To be effective, load control programs require information about the characteristics of the devices controlled, and more information (such as real-time data) allows load control to be more effective (Mathieu et al. 2013). Such information sharing raises questions about consumer privacy concerns, since some consumers may be unwilling to share appliance or household-level energy consumption data (Krishnamurti et al. 2012; McKenna et al. 2012; Gromet et al. 2013; Naus et al. 2014; Buchanan et al. 2016). Participation in direct load control programs is also likely to be influenced by consumer trust in the technology and the utility or aggregator managing the program (Balta-Ozkan et al. 2013; Stenner et al. 2017). As with other smart grid technologies, the choice of appropriate frames in communications with consumers is likely to influence decisions to participate in such programs (Broman Toft et al. 2014). Although some households may be unlikely to participate in load control programs due to concerns about information sharing or other reasons, partial adoption still provides benefits to the power system (Mathieu et al. 2015). Accordingly, it is important to understand who may prefer to participate in load control programs and what characteristics of the programs, when communicated to consumers, are associated with greater willingness to participate.

This study examines public attitudes toward several different aspects of load information sharing and control. Our first research question focuses on understanding how different sets of potential benefits affect willingness to share static and dynamic information about refrigerators and participate in refrigerator control programs. Potential benefits include reduced electricity 
bills, improved grid reliability, reduced air pollution, and reduced carbon emissions. Our second research question focuses on how willingness to participate varies based on the extent of information sharing or control. Finally, we examine how demographic characteristics-including age and gender — and geographic location influence participants' willingness to share load information and participate in load control programs.

\section{Methods}

We conducted a survey experiment using Google Consumer Surveys (GCS) targeted to the U.S. general population age 18 and over. GCS is an internet survey platform that can rapidly collect data from representative samples of the internet-using population at lower cost than traditional telephone, mail, or internet panel survey methods (a single-question U.S. national survey is $\$ .10$ per completed response as of December 2017). As traditional telephone and mail surveys have experienced declining response rates (Brick and Williams 2013), online survey tools are an alternative method increasingly used to reach representative samples of the population (Chang and Krosnick 2009; Ansolabehere and Schaffner 2014). Initial results have suggested that GCS is also an effective platform for conducting social science survey experiments (Santoso et al. 2016).

GCS selects a stratified sample of Internet users from a range of sites in Google's advertising network. Sampled users are presented with the option of answering a small number (1-10) of survey questions in order to access content on the publisher site in lieu of purchasing the content or viewing ads. Respondents may opt out at any time with no penalty. To achieve geographic and demographic representativeness, GCS applies weights based on Census Current Population Survey frequencies for respondents' inferred demographic categories, including age, 
gender, income, and location. Location data at the state and regional level are available for most responses (locations are inferred based on IP addresses).

Our survey experiment was fielded May 26 and 27, 2015. Four descriptions of possible benefits were paired with three levels of information sharing/control to create a $3 \times 4$ factorial between-subjects design, which resulted in 12 different survey questions (Table 1). To attract respondents' attention and enhance the salience of the question, an image of a refrigerator was included in each question. Each question was fielded separately, with target samples of $\mathrm{N}=250$ completed responses per question (total $\mathrm{N}=3003$ ). Across all 12 questions, the average response rate was $17 \%$, similar to that of other GCS-based surveys (McDonald et al. 2012). Inferred gender was available for $83 \%$ of respondents, of which $56 \%$ were male, as compared to $49 \%$ of the total U.S. population age 18 and older in 2015 (U.S. Census Bureau 2016). Inferred age was available for $76 \%$ of respondents in six categories: $18-24$ (17\% [as compared to $13 \%$ of the total adult population]), 25-34 (19\% [18\%]), 35-44 (16\% [16\%]), 45-54 (17\% [17\%]), 55-64 (18\% $[16 \%])$, and $65+(14 \%[19 \%])$. Respondents missing inferred age or gender data were categorized as "unknown" for that variable rather than being dropped from the analysis. Location data (state and census region) were available for all but 13 responses (99\%), with $27 \%$ of respondents located in the Midwest (as compared to $21 \%$ of the total adult population), $17 \%$ in the Northeast (18\%), 30\% in the South (37\%), and 26\% in the West (23\%). We analyze message treatment effects on willingness to participate using a multilevel logistic regression model, treating gender, age, and region as random effects to both control for possible geographic and demographic non-representativeness and examine each variable's marginal effects. We treat each possible type of benefit and each level of information sharing/control as fixed effects. We first model only demographic predictors (model 1) and subsequently add treatment conditions in a 
full model (model 2), which also includes interactions between treatment conditions and significantly varying demographic predictors. The multilevel models were fit in $\mathrm{R}$ using the lme4 package (Bates et al. 2014).

After fitting the above models, we can apply or "poststratify" the fitted model to the national population (or specific geographic areas) to simulate the proportion of the population who would be expected to be willing to share data or participate in load control according to each treatment condition. We use county-level census data from the 2015 5-year American Community Survey (ACS) (U. S. Census Bureau 2016). Specifically, we use the cross-tabulated variable "tenure by age of householder," which contains counts of owner or renter-occupied households by the age of the primary householder. The Census Bureau defines the primary householder as the person "in whose name the housing unit is owned or rented," which serves as a proxy for the person who would be making the decision to participate in an electric load control program were one available (U. S. Census Bureau 2016). For our estimates, we select only householders in owner-occupied housing units, assuming that renter-occupied householders are unlikely to be able to enroll in an appliance-based load control program.

\section{Results}

Depending on the question wording, between $29 \%$ and $53 \%$ of respondents overall expressed willingness to share load information or participate in load control (Table 2). Regression model results indicated that both respondent demographics and message conditions were associated with variation in willingness to participate in the described load control programs (Table 3). Among these predictors, the type of benefit described in the question, the level of information sharing or control described, and respondent age were all significantly $(\mathrm{p}<0.05)$ associated with respondents' willingness to participate (Figure 1). 
Describing reduced air pollution as the benefit of participation was associated with significantly higher willingness to participate than describing reduced electricity bills as the benefit (mean difference: 5 percentage points; $\mathrm{p}=0.02$ ). The benefit of reduced carbon emissions was also associated with somewhat higher willingness to participate, although the difference was marginally significant (mean difference: 4 percentage points, $\mathrm{p}=0.05$ ). Willingness to participate did not differ when comparing improved power grid reliability and reduced electricity bills as the stated benefits of participation.

The level of information sharing or control described in the question was also significantly associated with differences in willingness to participate. Respondents were much more likely to be willing to share static information (i.e., the make and model of their refrigerator) as compared to sharing dynamic information (i.e., allowing temperature monitoring) (mean difference: 13 percentage points; $\mathrm{p}<0.001$ ) or participating in load control (i.e., temperature management within a set range) (mean difference: 14 percentage points). However, the load control condition was not associated with significantly different willingness to participate than the dynamic information sharing condition. Holding all other variables constant, predicted participation in static information sharing was $47 \%$, as compared to $34 \%$ in dynamic information sharing and $33 \%$ in load control.

Respondents' geographic region was not associated with significant differences in willingness to participate independent of other predictors, nor was their inferred gender. However, we found large differences in willingness to participate across inferred age groups. The youngest respondents $(18-24,25-34)$ were significantly more likely to participate than older respondents. Averaging across all treatment conditions, predicted participation was $66 \%$ among 18-24 year old respondents and 57\% among 25-34 year old respondents, significantly higher than 
all other age groups. By comparison, predicted participation was lowest among 55-64 year old respondents at $24 \%$. For a load control program described as letting the utility "manage your refrigerator's temperature within a range you set," 64\% of 18-24 year old respondents and 54\% of 25-34 year olds are predicted to be willing to participate in the program if reducing air pollution is described as the benefit of participation, as compared to $21 \%$ of respondents $55-64$ years old and $26 \%$ of respondents 65 years or older.

Applying our model to population statistics for owner-occupied householders crosstabulated by age indicates that $29 \%$ of owner-occupied householders nationwide would respond "yes" to the question "[i]f it could reduce air pollution, would you let your utility manage your refrigerator's temperature within a range you set?” By comparison, 25\% nationwide would respond "yes" to the question "[i]f it could reduce your electricity bill, would you let your utility manage your refrigerator's temperature within a range you set?" However, given the substantial variation by age group in responses, places with greater proportions of younger householders would exhibit greater rates of adoption of load control programs than places with fewer younger householders. This geographic variation in demographic composition within the U.S. is evident in a county-level map of our model estimates poststratified by age (Figure 2). Among counties with at least 10,000 owner-occupied households, accounting for variation in the age of owneroccupied householders indicates estimated participation ranging from 34\% in Onslow County, North Carolina to $25 \%$ in Sumter County, Florida under the "reduce air pollution" message treatment. Among the largest counties by population (those with at least 100,000 households), estimated participation ranges from 33\% in Utah County, Utah to 26\% in Sarasota County, Florida. 


\section{Discussion}

Variation in willingness to share load information or participate in load control programs was most strongly associated with the age of respondents, the level of information sharing or control, and the type of benefit described as resulting from participation. Program descriptions that include environmental benefits (reduced greenhouse gas emissions, reduced air pollution) were associated with greater willingness to share/participate as opposed to alternative incentives, such as reduced electricity bills or improved grid reliability, although the magnitude of the difference was small. Results also show that respondents are more willing to share static load information (i.e., the make and model of one's refrigerator) than dynamic load information or participate in load control. Willingness to share dynamic load information and participate in load control was comparable. These results are consistent with previous findings that about one-third of participants in a U.K. study would agree to participate in direct load control for their home heating system (Fell et al. 2015).

Importantly, an individual demographic characteristic — age — was the strongest predictor of willingness to share load information or participate in a refrigerator load control program, with a much stronger effect than either the type of benefit or level of participation. Although generally only about one-third of respondents were willing to participate in the refrigerator load control program described in the survey experiment, willingness to participate rises to greater than half of respondents among those between the ages of 18 and 34 . This variation suggests that targeting programs to areas with greater proportions of younger householders, or targeting within broader populations to younger householders, may increase the likelihood of recruitment for utilities interested in deploying load control programs. Just as we show that variation in load control program participation can be predicted by householder age, variation in household 
energy consumption and electricity load profiles can also be predicted by household demographic characteristics including age (McLoughlin et al. 2015; Frederiks et al. 2015a). Even partial adoption of a load control program by a subset of customers within a utility service area can provide benefits to the power system. For example, Mathieu et al. (2015) estimate the technical potential of residential load control in California to be more than $10 \mathrm{GW}$, which is more than 7 times California's 1.325 GW Energy Storage Mandate (CPUC 2013) designed to enable balancing of increased penetration levels of intermittent renewable energy sources. Therefore, the participation of only $14 \%$ of California households is needed to exceed the mandate.

Future work should extend these initial findings that individual differences and descriptions of environmental benefits are associated with different preferences, particularly to examine other individual factors related to residential energy consumption that may also help to identify customers who would be willing to participate in load control programs (Gromet et al. 2013; Frederiks et al. 2015b, a). Although we did not find broad regional geographic variation in willingness to participate beyond differences due to demographic composition, geographic variation may be present at finer scales and could improve the ability to model individual preferences since attitudes about renewable energy and climate change exhibit strong variation within U.S. states and regions (Howe et al. 2015). Models that can predict variation in willingness to participate in load control programs would improve targeting of the programs, enabling integration of higher penetrations of renewable energy resources into the grid.

\section{Conclusions}

Load control programs, if adopted by consumers, can facilitate policy goals of increased grid penetration of renewable energy sources. The ability to participate in load control programs 
can also expand the range of household-level actions individuals can take to reduce their own carbon footprint and associated environmental impacts of energy usage (Dietz et al. 2009). As we show, such environmental benefits may also be effective in eliciting participation in load control programs by the public. These results are consistent with previous research showing that energy-related behaviors are related to individual environmental concern (Spence et al. 2014, 2015; Asensio and Delmas 2015). Among the general population, describing the environmental benefits of load information sharing/control may be more effective than economic incentives alone at promoting participation. Further, the strong differences in willingness to participate across age groups suggest that demographically targeted communication efforts could be most successful in eliciting participation. 


\section{Tables}

Table 1: Survey questions in each message treatment condition.

\begin{tabular}{ll}
\hline 1A & $\begin{array}{l}\text { If it could reduce your electricity bill, would you share the make and model of your } \\
\text { refrigerator with your utility company? }\end{array}$ \\
\cline { 2 - 2 } 1B & $\begin{array}{l}\text { If it could improve power grid reliability, would you share the make and model of your } \\
\text { refrigerator with your utility company? }\end{array}$ \\
\cline { 2 - 2 } 1C & $\begin{array}{l}\text { If it could reduce air pollution, would you share the make and model of your refrigerator } \\
\text { with your utility company? }\end{array}$ \\
\cline { 2 - 2 } 1D & $\begin{array}{l}\text { If it could reduce carbon emissions, would you share the make and model of your } \\
\text { refrigerator with your utility company? }\end{array}$ \\
\hline 2A & $\begin{array}{l}\text { If it could reduce your electricity bill, would you let your utility company monitor the } \\
\text { temperature of your refrigerator? }\end{array}$ \\
\cline { 2 - 2 } 2B & $\begin{array}{l}\text { If it could improve power grid reliability, would you let your utility company monitor the } \\
\text { temperature of your refrigerator? }\end{array}$ \\
\cline { 2 - 2 } 2C & $\begin{array}{l}\text { If it could reduce air pollution, would you allow your utility company monitor the } \\
\text { temperature of your refrigerator? }\end{array}$ \\
2D & $\begin{array}{l}\text { If it could reduce carbon emissions, would you allow your utility company monitor the } \\
\text { temperature of your refrigerator? }\end{array}$ \\
\hline 3A & $\begin{array}{l}\text { If it could reduce your electricity bill, would you let your utility manage your refrigerator's } \\
\text { temperature within a range you set? }\end{array}$ \\
\cline { 2 - 2 } 3B & $\begin{array}{l}\text { If it could improve power grid reliability, would you let your utility manage your } \\
\text { refrigerator's temperature within a range you set? }\end{array}$ \\
3C & $\begin{array}{l}\text { If it could reduce air pollution, would you let your utility manage your refrigerator's } \\
\text { temperature within a range you set? }\end{array}$ \\
3D & $\begin{array}{l}\text { If it could reduce carbon pollution, would you let your utility manage your refrigerator's } \\
\text { temperature within a range you set? }\end{array}$ \\
\hline
\end{tabular}

Table 2: Responses across all message treatment conditions.

\begin{tabular}{llll}
\multirow{2}{*}{ Information or control treatment condition } & & \multicolumn{2}{c}{ Answer } \\
\cline { 2 - 4 } 1: Share make \& model of refrigerator & A: reduce bill & No & \multicolumn{1}{c}{ Yes } \\
\cline { 2 - 4 } & B: improve grid reliability & $53.8 \%$ & $46.2 \%$ \\
\cline { 2 - 4 } & C: reduce air pollution & $46.8 \%$ & $43.2 \%$ \\
\cline { 2 - 4 } & D: reduce carbon emissions & $54.0 \%$ & $46.0 \%$ \\
\hline 2: Monitor temperature of refrigerator & A: reduce bill & $69.7 \%$ & $30.3 \%$ \\
\cline { 2 - 4 } & B: improve grid reliability & $67.2 \%$ & $32.8 \%$ \\
\cline { 2 - 4 } & C: reduce air pollution & $65.2 \%$ & $34.8 \%$ \\
\cline { 2 - 4 } s. Manage temperature of refrigerator within & D: reduce carbon emissions & $61.4 \%$ & $38.6 \%$ \\
\cline { 2 - 4 } & A: reduce bill & $69.6 \%$ & $30.4 \%$ \\
\cline { 2 - 4 } & B: improve grid reliability & $70.8 \%$ & $29.2 \%$ \\
\cline { 2 - 4 } & C: reduce air pollution & $65.2 \%$ & $34.8 \%$ \\
\cline { 2 - 4 } & D: reduce carbon emissions & $64.4 \%$ & $35.6 \%$ \\
\hline
\end{tabular}


Table 3: Summary of multilevel logistic regression models. Model 1 includes demographic predictors only. Model 2 adds message condition predictors and an interaction between message condition and respondent age.

\begin{tabular}{|c|c|c|c|c|c|c|}
\hline & \multicolumn{3}{|c|}{ Model 1} & \multicolumn{3}{|c|}{ Model 2} \\
\hline & Odds Ratio & Conf. Int. & $p$ & Odds Ratio & Conf. Int. & $p$ \\
\hline \multicolumn{7}{|l|}{ Fixed effects } \\
\hline (Intercept) & 0.62 & $0.47-0.80$ & $<.001$ & 0.85 & $0.66-1.09$ & .19 \\
\hline \multicolumn{7}{|l|}{ Benefit condition $^{a}$} \\
\hline B: improve grid reliability & & & & 0.98 & $0.79-1.22$ & .85 \\
\hline C: reduce air pollution & & & & 1.29 & $1.04-1.59$ & .02 \\
\hline D: reduce carbon emissions & & & & 1.24 & $1.00-1.53$ & .05 \\
\hline \multicolumn{7}{|l|}{ Information/control condition ${ }^{\mathrm{b}}$} \\
\hline Monitor temperature & & & & 0.54 & $0.42-0.70$ & $<.001$ \\
\hline Manage temperature & & & & 0.51 & $0.39-0.68$ & $<.001$ \\
\hline \multicolumn{7}{|l|}{$\begin{array}{l}\text { Random effects } \\
\text { Variance }\end{array}$} \\
\hline age & & 0.109 & & & & \\
\hline benefit*information / age & & & & & 0.502 & \\
\hline region & & 0.002 & & & 0.001 & \\
\hline gender & & 0.000 & & & 0.000 & \\
\hline \multicolumn{7}{|l|}{ Levels } \\
\hline age & & 7 & & & 7 & \\
\hline region & & 5 & & & 5 & \\
\hline gender & & 3 & & & 3 & \\
\hline Observations & & 3003 & & & 3003 & \\
\hline Deviance & & 3900.2 & & & 3784.3 & \\
\hline
\end{tabular}

a reference category is "A: reduce bill"

"reference category is "Share make and model" 


\section{Figures}
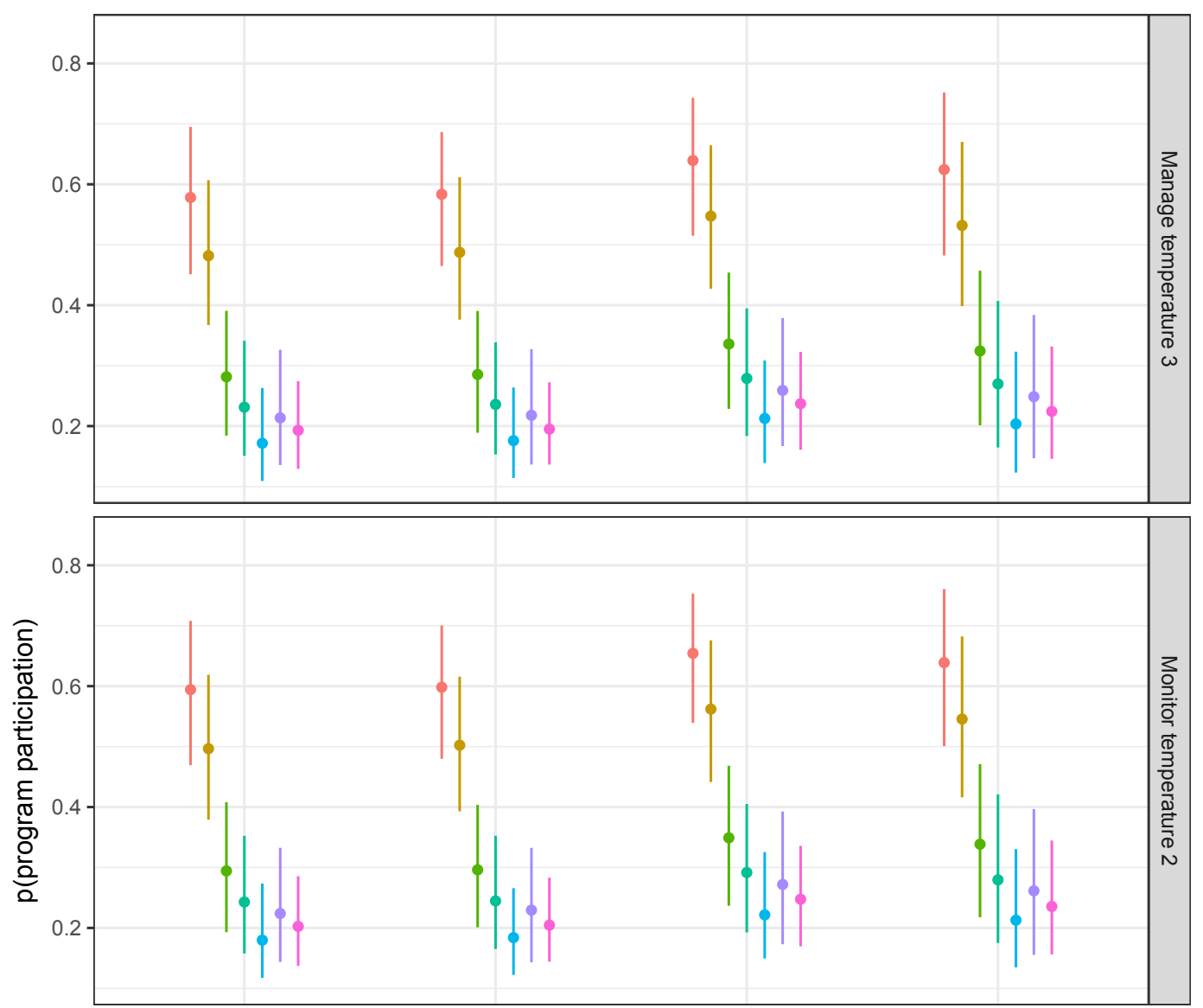

Respondent

age

1 18-24

+ 25-34

+ $35-44$

\ 45-54

\ 55-64

+ 65+

Unknown

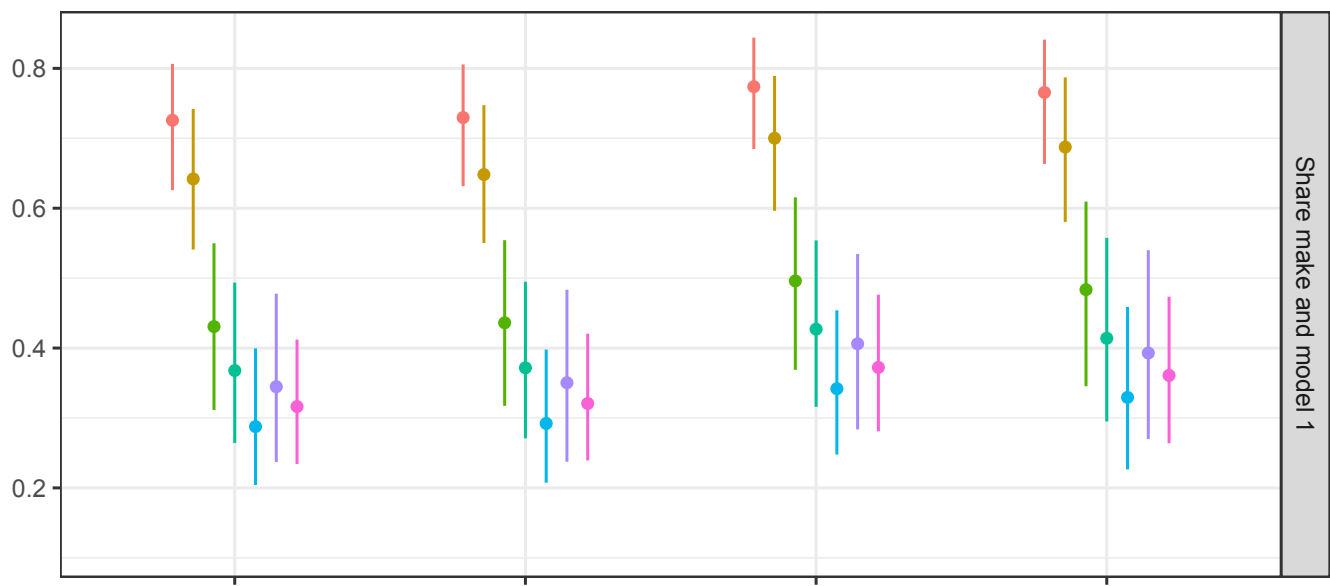

A: reduce bill

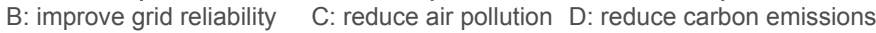

Benefit condition

Figure 1: Predicted probabilities of willingness to participate in refrigerator load control program ("yes" response), by described benefit condition, information/control condition, and respondent age. Error bars represent 95 percent confidence prediction intervals based on 999 simulations. Estimates based on regression model 2. 


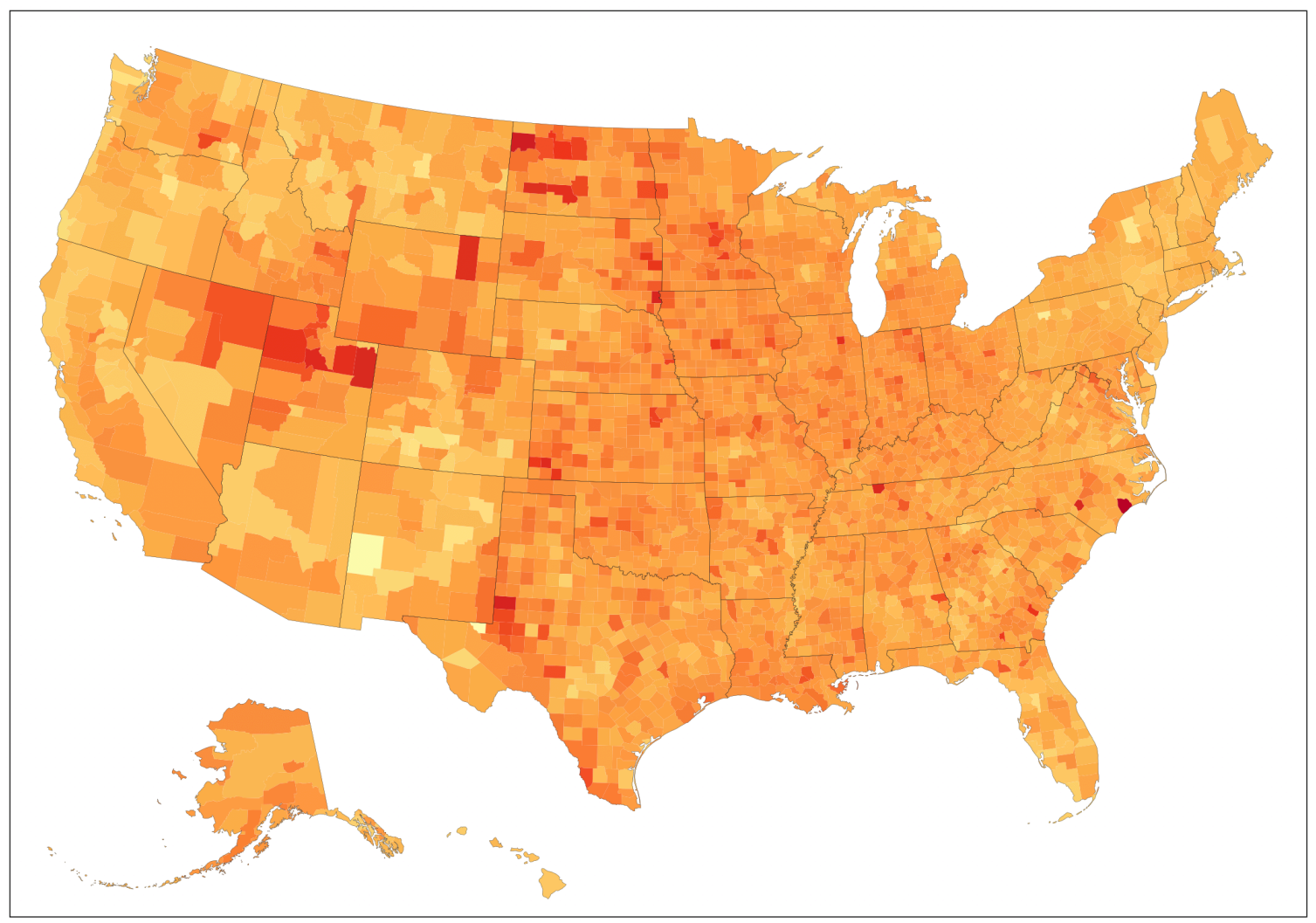

Estimated participation among owner-occupied householders (\%)

$\begin{array}{llllll}24 & 26 & 28 & 30 & 32 & 34\end{array}$

Figure 2: Estimates of agreement to the question "[i]f it could reduce air pollution, would you let your utility manage your refrigerator's temperature within a range you set?" Estimates are poststratified by age group and region at the county level for all U.S. counties or countyequivalents among owner-occupied householders only. 


\section{References}

Ansolabehere S, Schaffner BF (2014) Does Survey Mode Still Matter? Findings from a 2010 Multi-Mode Comparison. Polit Anal 22:285-303. doi: 10.1093/pan/mpt025

Asensio OI, Delmas MA (2015) Nonprice incentives and energy conservation. Proc Natl Acad Sci 112:E510-E515. doi: 10.1073/pnas.1401880112

Balta-Ozkan N, Davidson R, Bicket M, Whitmarsh L (2013) Social barriers to the adoption of smart homes. Energy Policy 63:363-374. doi: 10.1016/j.enpol.2013.08.043

Bates D, Maechler M, Bolker B, et al (2014) lme4: Linear mixed-effects models using Eigen and S4

Brick JM, Williams D (2013) Explaining Rising Nonresponse Rates in Cross-Sectional Surveys. Ann Am Acad Pol Soc Sci 645:36-59. doi: 10.1177/0002716212456834

Broman Toft M, Schuitema G, Thøgersen J (2014) The importance of framing for consumer acceptance of the Smart Grid: A comparative study of Denmark, Norway and Switzerland. Energy Res Soc Sci 3:113-123. doi: 10.1016/j.erss.2014.07.010

Buchanan K, Banks N, Preston I, Russo R (2016) The British public's perception of the UK smart metering initiative: Threats and opportunities. Energy Policy 91:87-97. doi: 10.1016/j.enpol.2016.01.003

Callaway DS, Hiskens IA (2011) Achieving Controllability of Electric Loads. Proc IEEE 99:184-199. doi: 10.1109/JPROC.2010.2081652

Chang L, Krosnick JA (2009) National surveys via RDD telephone interviewing versus the internet: comparing sample representativeness and response quality. Public Opin Q 73:641-678. doi: $10.1093 / \mathrm{poq} / \mathrm{nfp} 075$

CPUC (2013) Decision adopting energy storage procurement framework and design program. California Public Utilities Commission.

Demski C, Butler C, Parkhill KA, et al (2015) Public values for energy system change. Glob Environ Change 34:59-69. doi: 10.1016/j.gloenvcha.2015.06.014

Dietz T, Gardner GT, Gilligan J, et al (2009) Household actions can provide a behavioral wedge to rapidly reduce US carbon emissions. Proc Natl Acad Sci 106:18452-18456. doi: 10.1073/pnas.0908738106

Fell MJ, Shipworth D, Huebner GM, Elwell CA (2015) Public acceptability of domestic demand-side response in Great Britain: The role of automation and direct load control. Energy Res Soc Sci 9:72-84. doi: 10.1016/j.erss.2015.08.023

Frederiks ER, Stenner K, Hobman EV (2015a) The Socio-Demographic and Psychological Predictors of Residential Energy Consumption: A Comprehensive Review. Energies 8:573-609. doi: $10.3390 /$ en 8010573 
Frederiks ER, Stenner K, Hobman EV (2015b) Household energy use: Applying behavioural economics to understand consumer decision-making and behaviour. Renew Sustain Energy Rev 41:13851394. doi: 10.1016/j.rser.2014.09.026

Gromet DM, Kunreuther H, Larrick RP (2013) Political ideology affects energy-efficiency attitudes and choices. Proc Natl Acad Sci 110:9314-9319. doi: 10.1073/pnas.1218453110

Howe PD, Mildenberger M, Marlon JR, Leiserowitz A (2015) Geographic variation in opinions on climate change at state and local scales in the USA. Nat Clim Change 5:596-603. doi: $10.1038 /$ nclimate 2583

Katzenstein W, Apt J (2009) Air Emissions Due To Wind And Solar Power. Environ Sci Technol 43:253-258. doi: 10.1021/es801437t

Krishnamurti T, Schwartz D, Davis A, et al (2012) Preparing for smart grid technologies: A behavioral decision research approach to understanding consumer expectations about smart meters. Energy Policy 41:790-797. doi: 10.1016/j.enpol.2011.11.047

Mathieu JL, Dyson MEH, Callaway DS (2015) Resource and revenue potential of California residential load participation in ancillary services. Energy Policy 80:76-87. doi: 10.1016/j.enpol.2015.01.033

Mathieu JL, Koch S, Callaway DS (2013) State Estimation and Control of Electric Loads to Manage Real-Time Energy Imbalance. IEEE Trans Power Syst 28:430-440. doi: 10.1109/TPWRS.2012.2204074

McDonald P, Mohebbi M, Slatkin B (2012) Comparing Google Consumer Surveys to Existing Probability and Non-Probability Based Internet Surveys. Google White Paper

McKenna E, Richardson I, Thomson M (2012) Smart meter data: Balancing consumer privacy concerns with legitimate applications. Energy Policy 41:807-814. doi: 10.1016/j.enpol.2011.11.049

McLoughlin F, Duffy A, Conlon M (2015) A clustering approach to domestic electricity load profile characterisation using smart metering data. Appl Energy 141:190-199

Naus J, Spaargaren G, van Vliet BJM, van der Horst HM (2014) Smart grids, information flows and emerging domestic energy practices. Energy Policy 68:436-446. doi:

10.1016/j.enpol.2014.01.038

Santoso LP, Stein R, Stevenson R (2016) Survey Experiments with Google Consumer Surveys: Promise and Pitfalls for Academic Research in Social Science. Polit Anal 24:356-373. doi:

10.1093/pan/mpw016

Schuitema G, Ryan L, Aravena C (2017) The Consumer's Role in Flexible Energy Systems: An Interdisciplinary Approach to Changing Consumers' Behavior. IEEE Power Energy Mag 15:5360. doi: 10.1109/MPE.2016.2620658

Spence A, Demski C, Butler C, et al (2015) Public perceptions of demand-side management and a smarter energy future. Nat Clim Change 5:550-554. doi: 10.1038/nclimate2610 
Spence A, Leygue C, Bedwell B, O’Malley C (2014) Engaging with energy reduction: Does a climate change frame have the potential for achieving broader sustainable behaviour? J Environ Psychol 38:17-28. doi: 10.1016/j.jenvp.2013.12.006

Stenner K, Frederiks ER, Hobman EV, Cook S (2017) Willingness to participate in direct load control: The role of consumer distrust. Appl Energy 189:76-88. doi: 10.1016/j.apenergy.2016.10.099

U. S. Census Bureau (2016) 2011-2015 American Community Survey 5-Year Estimates. U. S. Census Bureau

U.S. Census Bureau (2016) Annual Estimates of the Resident Population for Selected Age Groups by Sex for the United States, States, Counties and Puerto Rico Commonwealth and Municipios: April 1, 2010 to July 1, 2015. U.S. Census Bureau

Vuylsteke G, Mathieu JL, Howe PD (2015) Environmental and economic benefits of non-disruptive demand response as a function of consumer information sharing. In: North American Power Symposium (NAPS), 2015. pp 1-6 